\title{
Visual impairment and socioeconomic factors
}

\author{
P M Livingston, C A McCarty, H R Taylor
}

\begin{abstract}
Background-Information about socioeconomic factors associated with visual impairment can assist in the design of intervention programmes. Such information was collected by the Melbourne Visual Impairment Project (Melbourne VIP).

Methods-The Melbourne VIP was a population based study of noninstitutionalised permanent residents in nine suburbs of the Melbourne metropolitan area aged 40 years of age and older. A standardised eye examination was provided to eligible residents which included a structured interview. Variables of interest for this analysis were age, sex, country of birth, language spoken at home, education level, use of private health insurance, employment status, and living arrangements. Visual impairment was defined as a best corrected visual acuity $<6 / 18$ and/or visual field constriction to within $20^{\circ}$ of fixation
\end{abstract}

Results-A total of 3271 (83\%) residents participated. Participants ranged in age from 40 to 98 years; $54 \%$ were female. Forty four (1.34\%) were classified as visually impaired due to visual acuity and/or visual field loss. To evaluate the independent association of the significant sociodemographic variables with visual impairment, a regression model was constructed that included age, retirement status, use of private health insurance, and household arrangement. The results showed that age was the significant predictor of visual impairment (OR: 3.19; CI: 2.29-4.43), with the mean age of people with visual impairment significantly older (75.0 years) compared with people without visual impairment (58.2 years) $(t$ test=9.71; $p=0.0001)$. Of the 44 visually impaired people, $39(87 \%)$ were aged 60 years of age and older.

Conclusion-The results indicate that age is the most significant factor associated with visual impairment. Of some importance was the finding that people with visual impairment were less likely to have private health insurance. With the aging of the population, the number of people affected by visual impairment will increase significantly. Intervention programmes need to be established before the onset of middle age to offset the escalation of visual impairment in the older population.

(Br F Ophthalmol 1997;81:574-577)
Despite the fact that it imposes a significant socioeconomic burden on society, little information is available on socioeconomic factors that may influence visual impairment. Few population based studies have investigated the role socioeconomic factors play in the development of visual impairment. ${ }^{1-5}$ Socioeconomic characteristics may highlight the socioeconomic burden of eye disease in the community and barriers to utilisation of eye services in subpopulation groups. This information is important to quantify the need for treatment and rehabilitative services, design innovative public health education and screening programmes that are targeted towards certain groups within the population, and identify priority areas of research.

The aim of this study was to explore which socioeconomic factors may be associated with visual impairment using data from the Melbourne Visual Impairment Project (Melbourne VIP).

Method

The Melbourne VIP was a population based survey of non-institutionalised permanent residents of the Melbourne metropolitan area aged 40 years or older. The detailed methodology has been reported elsewhere. ${ }^{67}$ In brief, nine pairs of adjacent census collector districts were randomly selected from the Melbourne Statistical Division. A door to door, household census was taken to identify all eligible peoplethat is, those aged 40 years or older in the calendar year of examination and who had lived at that address for 6 months or more.

Eligible individuals were invited to attend a local examination centre for a standardised ophthalmic examination and interview.

\section{EYE EXAMINATION}

Presenting visual acuity was measured with the participant's current distance correction, or if distant correction was not used, the unaided distant visual acuity was measured. If the presenting acuity was $<6 / 6$, refraction was undertaken. Best corrected visual acuity was determined after objective autorefraction and subjective refinement.

The visual field examination was performed with a Humphrey field analyser (HFA) (Humphrey Instruments Inc, San Leandro, CA, USA) on all capable participants. Participants not capable of performing the HFA test and those examined at their homes were tested with a Bjerrum screen. For those who were unable to perform a Bjerrum screen, visual fields were assessed by confrontation.
Accepted for publication 26 March 1997 
DEFINITION OF VISUAL IMPAIRMENT

Visual impairment was defined as a best corrected visual acuity $<6 / 18$ and/or visual field constriction to within $20^{\circ}$ of fixation in the better eye. ${ }^{8}$

\section{CASES AND CONTROLS}

A screening process was conducted on all participants during the eye examination. Participants identified during the visual acuity or visual field testing who had a best corrected visual acuity $<6 / 18$ and/or visual field constriction to within $20^{\circ}$ of fixation in the better eye were defined as cases. A participant qualified as a control if he/she was not visually impaired.

\section{SOCIODEMOGRAPHIC STATUS}

Sociodemographic status was classified from reported characteristics of the individual. Group characteristics refer to reported characteristics on median household income from information derived from the Australian $\mathrm{Bu}$ reau of Statistics. ${ }^{9}$ Sample areas were also compared.

For the purpose of this analysis, education level was divided into four mutually exclusive groups, 6 or less years (primary); greater than 6 but less than 12 years (secondary); trade apprenticeship; and tertiary education. Employment status was classified as currently employed (either full or part-time), retired or performing home duties; private health insurance was classified as either privately insured or not privately insured; language spoken at home was categorised as English speaking or other and country of birth was collapsed into Australian born or other. These socioeconomic factors were initially analysed individually before being condensed for the final model.

Data on household income were not collected because of the concerns of the potential negative impact the questions might have on participation. Age adjusted rates of visual impairment for each of the nine sample areas were calculated and compared with the median household income as reported in the 1991 census. ${ }^{9}$ Median household income for each sample area was determined from the Australian Bureau of Statistics, Basic Community Profile. $^{9}$

\section{STATISTICAL METHODS}

Statistical methods for univariate analyses included the $\chi^{2}$ test for comparing groups and $t$ test for comparing means. Multivariate analyses were performed using logistic regression to compute the relative odds of visual impairment for the different risk factors while controlling for potential confounders; analysis of covariance was conducted to compare means while controlling for confounders. Data analyses were performed using SAS (SAS Institute, Cary, NC, USA). Factors associated with visual impairment were considered statistically significant when $\mathrm{p}<0.05$.
Table 1 Univariate logistic regression assessing the odds of visual impairment associated with socioeconomic factors

\begin{tabular}{lcl}
\hline $\begin{array}{l}\text { Socioeconomic factors: } \\
\text { individual characteristics }\end{array}$ & Odds ratio & Confidence intervals \\
\hline $\begin{array}{l}\text { Born elsewhere } \\
\text { Other language spoken at }\end{array}$ & 1.23 & $0.70-2.40$ \\
$\quad$ home & 1.28 & $0.61-2.69$ \\
Sex (females) & 1.67 & $0.89-3.12$ \\
Education (secondary) & 1.84 & $0.95-3.54$ \\
No private health insurance & 2.43 & $1.29-4.56$ \\
Age (10 years) & 3.27 & $2.48-4.32$ \\
Living arrangement (alone) & 3.28 & $1.75-6.25$ \\
Education (trade) & 5.26 & $0.69-40.00$ \\
Education (tertiary) & 5.26 & $0.70-11.40$ \\
Retired & 10.31 & $3.17-33.33$ \\
\hline
\end{tabular}

\section{Results}

STUDY POPULATION AND PREVALENCE OF VISUAL IMPAIRMENT

A total of 4273 houses were identified in the nine study clusters. Of these 4033 (94\%) provided information and 2391 (59\%) had eligible residents. In the eligible houses there were 3946 eligible people of whom 3271 (83\%) agreed to participate. Non-English speaking people were significantly less likely to participate (odds ratio (OR): 0.61; confidence interval (CI): $0.48-0.77$ ), but there were no other significant differences between participants and non-participants and between participants and the Melbourne and Australian populations. ${ }^{10}$ The participants ranged in age from 40 to 98 years and $54 \%$ were female.

The prevalence of visual impairment is reported elsewhere. ${ }^{8}$ A total 44 (1.34\%) people were classified as visually impaired with best corrected visual acuity $<6 / 18$ and/or constriction of the visual field to within $20^{\circ}$ of fixation in the better eye.

FACTORS ASSOCIATED WITH VISUAL IMPAIRMENT Individual characteristics

To evaluate the univariate association of specific sociodemographic characteristics with visual impairment, several regression models were constructed that included age, sex, education level, retirement status, country of birth, main language spoken at home, use of private health insurance, and living arrangements (Table 1).

Another multivariate regression model was constructed which included the factors significant in the univariate analysis. The results showed that age was the only significant predictor of visual impairment (OR: 3.19; CI: 2.29-4.43). However, not having private health insurance approached statistical significance (OR: 1.65; CI: 0.86-3.20) (Table 2).

People with visual impairment were significantly older ( 75.0 years) compared with people without visual impairment (58.2 years) $(t$ test $=9.71 ; \mathrm{p}=0.0001)$. Further analyses

Table 2 Multivariate logistic regression assessing the odds of visual impairment associated with socioeconomic factors (individual characteristics)

Socioeconomic factors:

individual characteristics $\quad$ Odds ratio Confidence intervals

Living arrangement (alone) $1.04 \quad 0.51-2.12$

Retired $\quad 1.04 \quad 0.51-2.12$

Retired $1.51 \quad 0.41-5.58$

$\begin{array}{lll}\text { No private health insurance } & 1.65 & 0.86-3.20 \\ \text { Age (10 years) } & 3.19 & 2.29-4.43\end{array}$ 
Table 3 Prevalence of visual impairment by sample area

\begin{tabular}{ll}
\hline Sample area & Prevalence (\%) \\
\hline Windsor & 2.7 \\
Albert Park & 2.2 \\
Edithvale & 1.8 \\
East Bentleigh & 1.4 \\
Werribee & 1.6 \\
Frankston & 1.2 \\
Doncaster & 0.9 \\
Wantirna & 0.6 \\
Glenroy & 0.6 \\
\hline
\end{tabular}

indicated that of the 44 people visually impaired, $39(87 \%)$ were aged 60 years of age and older. People aged 60 years of age and older were 10 times more likely to have visual impairment compared with those aged under 60 years of age.

Thirty five per cent of people with visual impairment had private health insurance compared with $57 \%$ of people without private health insurance.

\section{Geographic location}

Visual impairment varied by geographic location (Table 3). However, this difference was not significant $\left(\chi^{2}=10.04 ; \mathrm{p}=0.26\right)$. Owing to the relatively small sample size in each test site, there was insufficient power to determine the local predictors of visual impairment by sample area. It was impossible to assess any clustering effects because too few cases resided in any sample area; however, all clusters showed an increase in visual impairment with increasing age.

\section{Median household income}

The distribution of the median household income is shown in Figure 1. Overall, people with visual impairment were more likely to live in an area where the median household income was less than $\mathrm{A} \$ 35000$ per year (Windsor, Albert Park, Werribee, and East Bentleigh) compared with people with median household incomes of $\$ 35000$ or more (Frankston, Edithvale, Glenroy, Wantirna, and Doncaster) $\left(\chi^{2}=30.90 ; p=0.001\right)$. People who lived in the

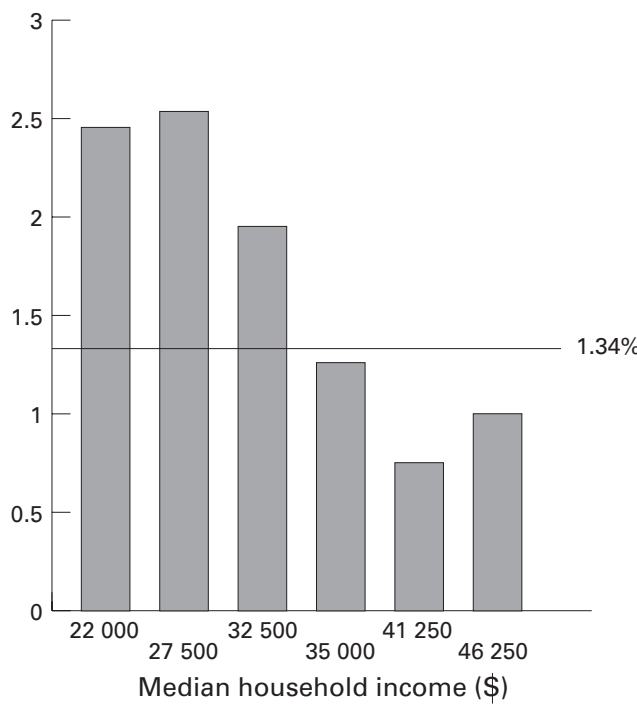

Figure 1 Visual impairment by median household income.
Table 4 Univariate logistic regression assessing the odds of visual impairment associated with median household income

\begin{tabular}{lll}
\hline $\begin{array}{l}\text { Median household income } \\
(A \$)\end{array}$ & Odds ratio & Confidence intervals \\
\hline$<35000$ & 1.00 & - \\
$\geqslant 35000$ & 0.68 & $0.37-1.25$ \\
\hline
\end{tabular}

sample area Windsor which had the lowest median household income (\$22 000) had twice the rate of visual impairment compared with overall sample rate of $1.34 \%$.

In the univariate analysis looking at visual impairment by median household income, the analysis showed that people were $68 \%$ less likely to have visual impairment if they lived in an area with a median household income of $\$ 35000$ or more. However, this difference was not significant (Table 4).

\section{Discussion}

Although the prevalence of visual impairment was low, the similarities between the Melbourne VIP with the Melbourne and Australian communities indicate that this level of impairment is representative of the Australian community. The Melbourne VIP age standardised rate of blindness (US definition $\leqslant 6 / 60$ ) was $0.34 \%$, which was not significantly different from other (age standardised to the Melbourne VIP) rates reported in white cohorts from three studies conducted in urban and rural areas in the United States - the Beaver Dam Eye Study $(0.42 \%),{ }^{3}$ the Baltimore Eye Survey (0.79\% in whites) ${ }^{11}$ and the Appalachian community $(0.61 \%) .{ }^{5}$ This rate was also similar to the rate from the Blue Mountains Eye Study in New South Wales $(0.39 \%) .^{12}$

Previous studies have analysed the role of individual characteristics to offer insight into the association between socioeconomic status and visual impairment. ${ }^{1-5}$ After adjustment for potential confounders, age was the most significant factor associated with visual impairment.

Deterioration of vision threatens one's independence and lifestyle. Good vision is a key element in one's ability to live an active and independent life. Informing the community of age related eye disease, regular eye examinations (that is, every 2 years after age 40 ), and appropriate treatment in the prevention of visual impairment needs to be tailored to an aging population.

Of importance was the finding that those who did not have private health insurance were at increased risk of being visually impaired, but this finding was not statistically significant. An additional 75 cases of visual impairment would have been necessary to demonstrate, with $80 \%$ power, the association between private health insurance and visual impairment. It is interesting to note that $45 \%$ of people in Australia over 55 years of age have private health insurance. ${ }^{9}$ The rate in this study was higher for those who did not have visual impairment $(57 \%)$ but was also lower among those who did have visual impairment (35\%). These percentages 
are much higher in the urban communities compared with $42 \%$ of people in rural communities who have private health insurance.

Use of private health insurance is also reflected by the economic circumstances of the individual. Only $32 \%$ of people in households with median household incomes less than $\$ 32500$ in Australia have private health insurance compared with $67 \%$ of those with median household incomes over $\$ 32500 .^{9}$ Little information is available on these economic considerations in Australia. These costs may reflect the issues of access and lack of economic resources to participate in preventive eye health care. Further research is required to ascertain the possible barriers to access of eye services among people who have the potential to develop visual impairment.

In previous studies education level, employment status, and living arrangement appeared to influence visual impairment. ${ }^{135}$ These socioeconomic factors were not demonstrated to be significantly associated with visual impairment in this analysis; however, this may be attributable to the small number of cases. Although an additional 115 cases would be necessary to demonstrate the significant importance of retirement status, the point estimates of the odds ratios indicate that being retired may have been associated with visual impairment.

It should be noted that although living alone and not having private health insurance were not significant in the multivariate analysis, this may be attributable to the variables being covariate - that is, people who are uninsured are alone and elderly. The Melbourne VIP found that $65 \%$ of people who lived alone and aged $60+$ did not have private health insurance compared with $45 \%$ of people, aged 60 years and older, who lived with others.

While it is recognised that there are some limitations in comparing group or sample area characteristics, such as the ecological bias, the information can be used to confirm trends from the individual characteristics. In the present study there was no significant difference between people with a median household income of less than $\$ 35000$ compared with households with a median household income over $\$ 35000$. However, this may be attributable to the small sample size. An additional 140 cases would have been necessary to demonstrate an effect of median household income with visual impairment. Australian evidence ${ }^{1314}$ suggests that the cost of services can be a great deterrent in the use of services by lower socioeconomic groups, although American researchers suggested that this situation may be attributable to the reduced earning potential of people with visual impairment. ${ }^{13}$ Further research is necessary to address this situation.

The implications of this research for health services planning and delivery are noteworthy. The Australian population is aging ${ }^{15}$ and as individuals grow older they are more likely to have impaired vision. Assuming age specific rates of visual impairment continue, population growth projections ${ }^{13}$ indicate, without intervention, the number of people with visual impairment will double over the next 25 years. $^{8}$

A planned, systematic, educational intervention programme needs to be designed and implemented to reduce the prevalence and incidence of visual impairment in the community. The aim should be to shift the emphasis away from the end stage of disease towards increased knowledge of the dangers associated with age related eye conditions. The aim must be to improve community awareness on the consequences of undiagnosed and untreated age related eye disease and how to access primary and secondary eye health care. This would also provide a more effective use of the eye healthcare system.

Education programmes need to be established before the onset of middle age to offset the escalation of visual impairment in the older population. This is an important goal in the promotion of preventative ophthalmic care in an aging population.

The authors wish to acknowledge the contributions of the following people: Ms Sharon Bayley, Ms Marie Bissinella, Dr Charles Guest, Ms Cara Jin, Ms Sharon Lee, Ms Claire McKean, Dr Yury Stanislavsky, Mrs Catherine Walker, and $\mathrm{Mr}$ Matthew Wensor. The Melbourne VIP is supported in part by the Victorian Health Promotion Foundation, the Ansell Ophthalmology Foundation, and the National Health and Medical Research Council, including the Sir John Eccles Award to Professor Hugh Taylor. We also acknowledge the support of
Carl Zeiss in their donation of Humphrey equipment for use by the project.

1 Klein R, Klein BEK, Jensen SC, Moss SE, Cruikshanks KJ The relation of socioeconomic factors to age-related cataract, maculopathy and impaired vision. Ophthalmology 1994;101:1969-79.

2 Salive ME, Guralnik J, Christen E W, Glynn RJ, Colsher P, Ostfeld AM. Functional blindness and visual impairment in older adults from three communities. Ophthalmology 1992;99:1840-7.

3 Klein R, Klein BEK, Linton KLP, DeMets DL. The Beaver Dam Eye study: visual acuity. Ophthalmology 1991;98: $1310-5$

4 Tielsch JM, Sommer A, Katz J, Quigley H, Ezrine S and the Baltimore Eye Survey Research Group. Socioeconomic status and visual impairment among urban Americans. Arch Ophthalmol 1991;109:637-41.

5 Dana MR, Tielsch JM, Enger C, Joyce E, Santoli JM, Taylor HR. Visual impairment in a rural Appalachian community. Prevalence and causes. $\mathcal{F A M A} 1990 ; 264: 2400-5$.

6 Livingston PM, Carson CA, Stanislavsky YL, Lee SE, Guest CS, Taylor HR. Methods for a population-based study: the Melbourne Visual Impairment Project. Ophthalmic Epidemiol 1994;1:139-48.

7 Livingston PM, Guest CS, Bateman A, Woodcock N, Taylor Livingston PM, Guest CS, Bateman A, Woodcock N, Taylor
HR. Cost effectiveness of recruitment methods in a population-based epidemiological study. Aust f Pub Health 994;18:314-8.

8 Taylor HR, Livingston PM, Stanislavsky YL, McCarty CA. Visual impairment in Australia: distance and near visual acuity and visual field findings of the Melbourne Visual Impairment Project. Am f Ophthalmol 1997;123:328-37.

9 Australian Bureau of Statistics. Basic Community Profile. Unpublished data; 1995.

10 Livingston PM, Lee SE, McCarty CA, Taylor HR. A comparison of participants with non-participants in a population-based epidemiologic study: the Melbourne Visual Impairment Project. Ophthalmic Epidemiol 1997 (in press).

11 Tielsch JM, Sommer A, Witt K, Katz J, Royall RM, Baltimore Eye Survey Research Group. Blindness and visual impairment in an American urban population. The

2 Attebo K, Mitchell P, Smith W. Visual acuity and the causes of visual loss in Australia. The Blue Mountains Eye Study. of visual loss in Australia. The Bl

13 Donnovan J, d'Espaignet E, Merton C, van Ommeren M, eds. Immigrants in Australia: a health profile. Australian Institute of Health and Welfare. Ethnic Health Series, No 1. Canberra: AGPS, 1992.

14 National Health Strategy. Inequalities in health. Issues Paper No 4. Melbourne: National Health Strategy; 1992.

15 Australian Bureau of Statistics. Projections of the populations of Australia, states and territories 1993 to 2041. Canberra: AGPS, 1994. 